\title{
The 10 bp duplication insertion/deletion in the promoter region within paired box 7 gene is associated with growth traits in cattle
}

\author{
Yunyun Jin ${ }^{1}$, Hanfang $\mathrm{Cai}^{1}$, Jiming $\mathrm{Liu}^{2}$, Fengpeng Lin $^{3}$, Xinglei Qi ${ }^{3}$, Yueyu Bai ${ }^{4}$, Chuzhao Lei ${ }^{1}$, \\ Hong Chen ${ }^{1}$, and Xianyong Lan ${ }^{1}$ \\ ${ }^{1}$ College of Animal Science and Technology, Northwest A\&F University, Shaanxi Key Laboratory of \\ Molecular Biology for Agriculture, Yangling, Shaanxi 712100, P. R. China \\ ${ }^{2}$ Animal Husbandry Technology Promotion Station of Jiangxi, Nanchang, Jiangxi 330000, P. R. China \\ ${ }^{3}$ Xianan Cattle Technology Development Company, Biyang, Henan 463700, P. R. China \\ ${ }^{4}$ Animal Health Supervision in Henan Province, Zhengzhou, Henan 450008, P. R. China
}

Correspondence to: Xianyong Lan (lanxianyong79@126.com) and Hong Chen (chenhong1212@126.com)

Received: 5 August 2016 - Revised: 31 October 2016 - Accepted: 3 November 2016 - Published: 21 November 2016

\begin{abstract}
Paired box 7 (Pax7) gene, a member of the paired box gene family, plays a critical role in animal growth and muscle development, especially in cell proliferation and self-renewal. The aim of this study was to detect the 10 base pair (bp) duplication insertion/deletion (indel) in the promoter region within the bovine $\operatorname{Pax} 7$ gene as well as its association with growth traits. Herein, a total of 718 individuals from five Chinese cattle breeds were sampled and detected. The $10 \mathrm{bp}$ duplication indel was found in these cattle breeds and there were three genotypes: II (insertion/insertion), ID (insertion/deletion), and DD (deletion/deletion). Moreover, this indel was significantly associated with the body weight in Xianan cattle $(P=0.006)$, the body height in Jinjiang cattle $(P=0.046)$, and the hip width in Pi'nan cattle $(P=0.020)$. Consistently, the individuals with II genotype showed better phenotypic traits than those with the other genotypes in these five breeds. These findings suggest that the $10 \mathrm{bp}$ duplication indel within the bovine Pax7 gene could be considered as an effective DNA molecular marker that provides valuable theoretical basis for marker-assisted selection (MAS) in beef cattle in the future.
\end{abstract}

\section{Introduction}

Pax genes, also known as the paired box genes in mammals, are a family comprising of nine genes (Lang et al., 2007; $\mathrm{Xu}, 2014)$. All family members possess a paired domain that recognizes specific DNA sequences, some of which have an additional, partial or whole homeodomain that also interacts with DNA (Lang et al., 2007). Based on the different structures and functions, these genes are divided into four groups (Lang et al., 2007). Among these, the paired box 7 (Pax7; see Appendix A for all abbreviations) gene belongs to the third group and has the most abundant structure in this family, including one paired domain, one homeodomain, one octapeptide motif and one transactivation $(\mathrm{Xu}, 2014)$.

Owing to the abundant structure, the $\operatorname{Pax} 7$ gene plays a critical role in organogenesis during embryonic development as well as growth and muscle development in animals, especially in cell proliferation and self-renewal (Lang et al., 2007). In the development of skeletal muscle that has strong regenerative capacity, the Pax 7 gene can promote cell proliferation and inhibit cell differentiation by combining with the specific genes related to cell growth and adhesion (Maltzahn et al., 2013), such as inducing the expression pattern of the $M y o D$ and Myf5 genes and co-regulating with the Pax3 gene (Bhagavati et al., 2007; Galli et al., 2008). Therefore, the Pax7 is a marker gene for muscle satellite cells (Buckingham and Rigby, 2014), which also is recognized as the target gene for the treatment of muscular diseases, including muscle development disorders, muscular dystrophy, and so on (Seale and Rudnicki, 2000). Additionally, during myoblast differentiation, Pax7 can be regulated by targeting with microRNAs related with growth and development (Xu et al., 2012), 
such as miR-1 (Chen et al., 2010), miR-206, miR-486 (Dey et al., 2011), and miR-682 (Chen et al., 2011). Moreover, the Pax7 gene has a vital role in the damage repair of muscle in humans (Hyatt et al., 2008), mice (Jostes et al., 1990), and fish (Minchin and Hughes, 2008; Seger et al., 2011). Therefore, it can be concluded that the Pax7 gene plays an indispensable role in animal growth.

Previous literature shows that the polymorphisms of the Pax7 gene also could affect the phenotypic traits in mammals. For example, in humans, 75 single nucleotide polymorphisms (SNPs) within the intragenic region of the Pax7 gene were associated with alveolar rhabdomyosarcoma which seriously inhibited the normal development of skeletal muscle (Davicioni et al., 2009); in cattle, a previous study from our group found that the SNPs within the bovine Pax7 gene, except in the promoter region, had significant effects on growth traits of Nanyang cattle breed (Xu et al., 2011, 2012), but the insertion/deletion (indel) variations in the $\operatorname{Pax} 7$ gene promoter region were unknown. Moreover, a 31 bp indel within the chicken $\operatorname{Pax} 7$ gene was significantly associated with body weight, which indicated that $\operatorname{Pax} 7$ should be considered as a candidate gene for growth traits (Zhang et al., 2014). Based on the genetic variants from high-throughput sequencing data and previous bioinformatics analysis in our group, we first found the 10 bp duplication indel in the Pax7 gene promoter region (Xu, 2014), however, there were few reports about the 10 bp duplication indel in the $\operatorname{Pax} 7$ gene promoter region and its association with growth traits in cattle.

Therefore, the objective of this study was aimed at exploring the $10 \mathrm{bp}$ duplication indel in the Pax7 gene promoter region in 718 individuals from five Chinese cattle breeds, as well as evaluating their effects on growth traits, which would provide useful information for marker-assisted selection (MAS) programs in the cattle breeding industry.

\section{Materials and methods}

The study protocol was approved by the Regulations for the Administration of Affairs Concerning Experimental Animals (Ministry of Science and Technology, China, revised in 2004) and approved by the Institutional Animal Care and Use Committee (College of Animal Science and Technology, Northwest A\&F University, China).

\subsection{DNA samples and data collection}

A total of 718 unrelated female adult cattle from five Chinese breeds: Xianan (XN, $n=169$ ), Ji' an (JA, $n=43$ ), Jinjiang (JJ, $n=82$ ), Guangfeng (GF, $n=70$ ), and Pi'nan (PN, $n=354$ ) were used in this study for initial indel discovery. All of these cattle breeds were reared in the provinces of Henan, Jiangxi, Jiangxi, Jiangxi, Henan, respectively. All animals were allowed access to feed and water ad libitum under normal conditions, as previously described (Yang et al., 2012; Dang et al., 2014; Zhang et al., 2015). Growth traits of the five cattle breeds include body height, hip height, body slanting length, body weight, chest circumference, waist circumference, cannon circumference, rump length, and hip width, which were collected as described in Gilbert et al. (1993).

\subsection{DNA isolation and genomic DNA pool construction}

Genomic DNA samples were extracted from ear tissue using standard salt-chloroform extraction protocol (Sambrook and Russell, 2001; Lan et al., 2007), and stored at $-80^{\circ} \mathrm{C}$. A total of 30 DNA samples were randomly selected to construct genomic DNA pools (Zhang et al., 2015; Cai et al., 2016; Shi et al., 2016). The chosen genomic DNA samples were diluted to the same concentration $\left(50 \mathrm{ng} \mu \mathrm{L}^{-1}\right)$ and individual aliquots of DNA samples were transferred into a single tube to ensure that a constant amount of each DNA sample was transferred to the pool. The pool was then mixed gently and uniformly. The genomic DNA pools were used as templates for PCR amplification and then amplified in different individuals (Sham et al., 2002; Zhang et al., 2015).

\subsection{Primer design and PCR amplification}

Based on the reference sequences in the NCBI database (GenBank accession no. AC_000159.1) and our unpublished data (Xu, 2014), Primer Premier 5.0 software was used to design the detected primers. One primer pair was listed as follows: forward primer (Pax7-F: 5'-CGCGTTACAACCAGCACTTC-3') and reverse primer (Pax7-R: 5'-GCCTTCTTTCTCCGACCAC-3'). Each PCR reaction was carried out in a $25 \mu \mathrm{L}$ reaction mixture that contained $50 \mathrm{ng}$ genomic DNA, $0.5 \mu \mathrm{mol} \mathrm{L}{ }^{-1}$ of each primer, $1 \times$ buffer (including $1.5 \mathrm{mM} \mathrm{MgCl}_{2}$ ), $200 \mu \mathrm{M}$ dNTPs (dATP, dTTP, dCTP, and dGTP), and 0.625 units of Taq DNA polymerase (MBI Fermentas, Vilnius, Lithuania) (Zhang et al., 2015). To reduce non-specific amplification, a touch-down PCR program was performed as follows: $5 \mathrm{~min}$ at $95^{\circ} \mathrm{C}, 18$ cycles of denaturing at $95^{\circ} \mathrm{C}$ for $30 \mathrm{~s}$, annealing at $68^{\circ} \mathrm{C}$ for $30 \mathrm{~s}$ and a decrease of $1^{\circ} \mathrm{C}$ per cycle, extension at $72^{\circ} \mathrm{C}$ for $20 \mathrm{~s}$, another 24 cycles of denaturing at $95^{\circ} \mathrm{C}$ for $30 \mathrm{~s}$, annealing at $60^{\circ} \mathrm{C}$ for $30 \mathrm{~s}$, extension at $72^{\circ} \mathrm{C}$ for $20 \mathrm{~s}$, and a final extension at $72^{\circ} \mathrm{C}$ for $10 \mathrm{~min}$ with subsequent cooling at $10^{\circ} \mathrm{C}$ (Zhang et al., 2015; Yang et al., 2016). The PCR products were detected by electrophoresis in $3.5 \%$ agarose gel stained with ethidium bromide at a constant voltage $(120 \mathrm{~V})$ for $80 \mathrm{~min}$. Then, the genotypes of the individuals were observed.

\subsection{Active site prediction of the $\operatorname{Pax} 7$ gene promoter region}

Firstly, the bovine $\operatorname{Pax} 7$ gene promoter sequences were retrieved from NCBI database. Secondly, JASPAR (http:// jaspar.genereg.net/cgi-bin/jaspar_db.pl), Genomatix MatIn- 
spector Release 8.0.4, and other online software were used to predict transcription factor binding sites in the promoter region of the $\operatorname{Pax} 7$ gene, as well as to determine the transcription factors that interacted with the $10 \mathrm{bp}$ duplication indel.

\subsection{Statistical analysis}

Genotypic and allelic frequencies of the bovine $\operatorname{Pax} 7$ gene were directly calculated (Xu et al., 2011). The heterozygosity $(\mathrm{He})$ of the population genetic diversity index was calculated according to Nei's method (Nei and Roychoudhury, 1974), the effective allele number (Ne) was calculated according to Morgante's formula (Morgante et al., 1994), and the polymorphism information content (PIC) was calculated via the website http://www.msrcall.com/Gdicall.aspx (Wu et al., 2014; Jia et al., 2015). The software program SPSS (version 18.0) (SPSS Inc., Chicago, USA) was used to make the goodness of fit tests for Hardy-Weinberg equilibrium (HWE) and analyze the relationship between the different types and the growth traits in the cattle breeds. All individuals were female adults and each fed the same nutritional diet in their farm. The basic linear model was used to evaluate the relationships between types and growth-related traits for each individual as follows: $Y=\mu+G+E$, where $Y$ was the trait measured for each animal, $\mu$ was the overall mean for each trait, $G$ was the effect of fixed factor genotype, and $E$ was the random error (Dang et al., 2014; Cai et al., 2016; Shi et al., 2016). The results are expressed as the means \pm SE. The differences were determined using analysis of variance (ANOVA), which was followed by the least significant difference (LSD) test. Differences between the means were considered significant at $P<0.05$.

\section{Results}

\subsection{Indel genotyping and genetic diversity}

The $10 \mathrm{bp}$ duplication indel was found in the promoter region of the Pax7 gene in all studied cattle breeds, which was described as AC_000159.1: insTCGTCTCCCC. Electrophoresis showed that there were three genotypes. Among them, the II genotype exhibited one band (218 bp), the DD genotype exhibited one band (208 bp), and the ID genotype exhibited two bands (218 and 208 bp) (Fig. 1). The frequency distributions of the three genotypes and the two alleles are summarized in Table 1, as well as the gene homozygosity (Ho), He, $\mathrm{Ne}$, and PIC. Above all, the frequencies of the ID genotype were the highest in JA, and then in the following decreasing order: XN, PN, JJ, and GF cattle breeds. The frequencies of II genotype were higher than that of DD and ID genotypes in GF. In addition, this loci was at Hardy-Weinberg equilibrium (HWE) in all studied breeds $(P>0.05)$.

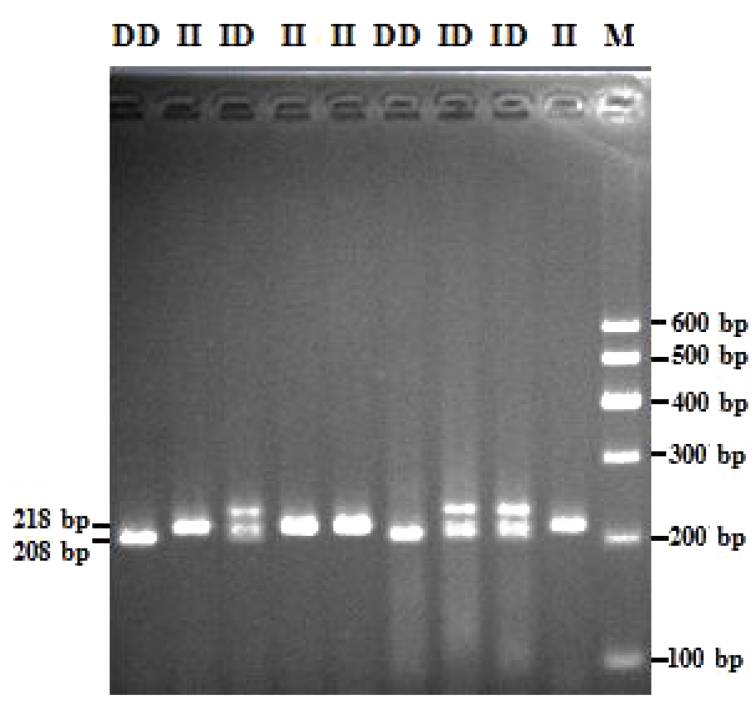

Figure 1. The electrophoresis pattern of $10 \mathrm{bp}$ duplication indel within the bovine Pax7 gene in cattle. Note: DD $=208 \mathrm{bp}$; $\mathrm{II}=218 \mathrm{bp} ; \mathrm{ID}=218 \mathrm{bp}+208 \mathrm{bp}$; and $\mathrm{M}=\mathrm{DNA}$ marker I.

\subsection{Association analysis of indel genotypes in five cattle breeds}

The association of the $10 \mathrm{bp}$ duplication indel in the promoter region within the $\operatorname{Pax} 7$ gene and growth traits is shown in Table 2. The analysis showed that this duplication indel was significantly associated with growth traits in three cattle breeds, e.g., the body weight in XN cattle $(P=0.006)$, the body height in $\mathrm{JJ}$ cattle $(P=0.046)$ as well as the hip width in PN cattle $(P=0.020)$. Consistently, the individuals with II genotype showed better phenotypic traits than others in all analyzed breeds. However, there was no significant relationship between this indel and growth traits in JA and GF cattle breeds (data not shown).

\subsection{Transcription factor binding site prediction of the Pax7 gene promoter region}

Considering that the indel sequence in the promoter region within the bovine $\operatorname{Pax} 7$ gene may cause transcription factor binding change, the transcription factor binding on the $10 \mathrm{bp}$ duplication indel sequence was predicted using the bioinformatics analysis software. The prediction results showed that there were some potential factors, such as zinc finger protein ZNF354C.

\section{Discussion}

The reported studies showed that several SNPs in introns and exons within the Pax7 gene had been reported in cattle and other species (Davicioni et al., 2009; Xu et al., 2011; Zhang et al., 2014). However, to date, the $10 \mathrm{bp}$ duplication indel in the promoter and it's association with economic 
Table 1. Genotypic and allelic frequencies and population indexes for $10 \mathrm{bp}$ duplication indel within the bovine Pax7 gene.

\begin{tabular}{|c|c|c|c|c|c|c|c|c|c|c|}
\hline \multirow[t]{2}{*}{ Breed } & \multicolumn{3}{|c|}{ Genotypic frequency } & \multicolumn{2}{|c|}{ Allelic frequency } & \multirow[t]{2}{*}{$\mathrm{Ne}$} & \multirow[t]{2}{*}{$\mathrm{He}$} & \multirow[t]{2}{*}{ Ho } & \multirow[t]{2}{*}{ PIC } & \multirow[t]{2}{*}{$P(\mathrm{HWE})$} \\
\hline & DD & ID & II & I & $\mathrm{D}$ & & & & & \\
\hline $\mathrm{XN}(n=169)$ & 0.355 & 0.527 & 0.118 & 0.382 & 0.618 & 1.894 & 0.472 & 0.528 & 0.361 & $>0.05$ \\
\hline $\mathrm{JA}(n=43)$ & 0.139 & 0.605 & 0.256 & 0.558 & 0.442 & 1.973 & 0.493 & 0.507 & 0.372 & $>0.05$ \\
\hline $\mathrm{JJ}(n=82)$ & 0.195 & 0.451 & 0.354 & 0.579 & 0.421 & 1.951 & 0.487 & 0.513 & 0.369 & $>0.05$ \\
\hline $\mathrm{GF}(n=70)$ & 0.157 & 0.400 & 0.443 & 0.643 & 0.357 & 1.849 & 0.459 & 0.541 & 0.354 & $>0.05$ \\
\hline $\mathrm{PN}(n=354)$ & 0.266 & 0.483 & 0.251 & 0.493 & 0.507 & 1.999 & 0.499 & 0.501 & 0.375 & $>0.05$ \\
\hline
\end{tabular}

Note: effective allele numbers (Ne), heterozygosity (He), homozygosity (Ho), polymorphism information content (PIC), Hardy-Weinberg equilibrium (HWE).

Table 2. Relationship between the 10 bp duplication indel within the Pax7 gene and growth traits (cm) in cattle breeds.

\begin{tabular}{llrrrr}
\hline Breed & Growth trait & \multicolumn{3}{c}{ Mean \pm SE } & $P$ value \\
\cline { 3 - 5 } & & II & DD & ID & \\
\cline { 3 - 5 } & & $114.37 \pm 7.16^{\mathrm{a}}$ & $110.18 \pm 5.48^{\mathrm{b}}$ & $110.61 \pm 5.94^{\mathrm{b}}$ & 0.046 \\
$\mathrm{JJ}$ & $\mathrm{BH}$ & $584.29 \pm 54.70^{\mathrm{A}}$ & $556.59 \pm 64.08^{\mathrm{AB}}$ & $543.16 \pm 49.33^{\mathrm{B}}$ & 0.006 \\
XN & BW & $46.84 \pm 4.04^{\mathrm{a}}$ & $45.37 \pm 3.84^{\mathrm{b}}$ & $45.43 \pm 4.41^{\mathrm{b}}$ & 0.020 \\
PN & HW & &
\end{tabular}

Note: values with different superscripts within the same column differ significantly at $P<0.05$ a, b and $P<0.01$ A, B

Body height (BH), body weight (BW), hip width (HW).

traits in cattle were rarely reported. Therefore, in this study, the duplication indel located at the promoter region within the bovine Pax7 gene was detected in Chinese cattle breeds (XN, JA, JJ, GF, and PN) and represented superior growth and meat traits (Yang et al., 2012). Interestingly, the $10 \mathrm{bp}$ duplication indel was found for the first time with three genotypes in the abovementioned cattle breeds. Moreover, this locus showed abundant genetic diversity as shown by the PIC values $(0.25<\mathrm{PIC}<0.5)$ in all studied breeds, as well as at HWE, which provided the solid foundation for carrying out association analysis.

To our knowledge, the promoter sequence is an important part of a gene regulatory region, which can regulate the expression of target genes by interacting with trans-acting factors (Mottagui-Tabar et al., 2005). Therefore, the polymorphisms in the promoter region may influence gene expression (Chorley et al., 2008; Aslan et al., 2012). Hence, the association analysis between $10 \mathrm{bp}$ duplication indel and growth traits in cattle were carried out. The association analysis implied that this indel had significant effects on different phenotypic traits (e.g., the body weight, body height and hip width) in XN cattle, JJ cattle, and PN cattle. This finding was consistent with many published studies about the promoter region mutations related to phenotypic traits in several species. In chicken, a SNP (g. $-640 \mathrm{C}>\mathrm{T}$ ) and a novel $61 \mathrm{bp}$ indel (g. $\left.-851 \_-790 \mathrm{del}\right)$ mutations within the promoter of transforming growth factor-beta 2 (TGFB2) gene were found to have significant effects on body weight (Tang et al., 2011). In pigs, two novel polymorphisms in the porcine adiponectin $(A D I P O Q)$ gene promoter, c. $-67 \mathrm{G}>\mathrm{A}$ and the $16 \mathrm{bp}$ indel
(c.-106_-91delGCCAGGGGTGTGAGCC) were showed to have outstanding correlations with loin measurement (Cieslak et al., 2013). In cattle, a SNP $(-274 C>$ G) in the SIRTI gene promoter region affected the gene expression level significantly and was markedly associated with Nanyang cattle body size (Li et al., 2013).

Furthermore, based on the association analysis, the individuals with II genotype consistently showed better growth traits in all studied breeds, suggesting that the "I" allele was the positive allele affecting the growth traits. This finding could be explained by the potential function of this promoter region binding the potential transcription factors. According to the bioinformatics analysis, this $10 \mathrm{bp}$ indel region might bind several critical transcription factors relating to growth and development, such as ZNF354C (Zfp354C). ZNF354C is an osteoblast-specific transcription factor that might take an active part in metabolism, cell proliferation, differentiation and development, and gene expression (Du and Hao, 2014; Wang et al., 2012; Buroker, 2016). ZNF354C specifically interacted with FAM20C and might also affect osteoblast differentiation by downregulating this factor (Du and Hao, 2014). Moreover, ZNF354C bound on the CTCCCC promoter sequences. In this study, "I" and "D" alleles possessed double and single copies of "CTCCCC", respectively. Therefore, ZNF354C could combine with different copies of "CTCCCC", which would affect the expression level of this gene, leading to a corresponding change in growth traits.

Briefly, the $10 \mathrm{bp}$ duplication indel of the promoter region within the Pax7 gene was identified to be significantly associated with cattle growth traits, which would further extend 
the genetic spectrum and provide an effective DNA marker for the MAS in beef cattle in the future.

\section{Data availability}

The original data are available upon request to the corresponding authors. 
Appendix A: Abbreviations

$\begin{array}{ll}\text { Pax7 } & \text { paired box 7 } \\ \text { indel } & \begin{array}{l}\text { insertion/deletion } \\ \text { insertion/insertion }\end{array} \\ \text { II } & \text { insertion/deletion } \\ \text { ID } & \text { deletion/deletion } \\ \text { DD } & \text { base pair } \\ \text { bp } & \text { single nucleotide polymorphism } \\ \text { SNP } & \text { marker-assisted selection } \\ \text { MAS } & \text { Hardy-Weinberg equilibrium } \\ \text { HWE } & \text { homozygosity } \\ \text { Ho } & \text { heterozygosity } \\ \text { He } & \text { effective allele numbers } \\ \text { Ne } & \text { polymorphism information content } \\ \text { PIC } & \text { polymerase chain reaction } \\ \text { PCR } & \text { Pi'nan cattle } \\ \text { PN } & \text { Xianan cattle } \\ \text { XN } & \text { Ji'an cattle } \\ \text { JA } & \text { Jinjiang cattle } \\ \text { JJ } & \text { Guangfeng cattle } \\ \text { GF } & \text { zinc finger protein 354C } \\ \text { ZNF354C } & \text { body height } \\ \text { BH } & \text { body weight } \\ \text { BW } & \text { hip width } \\ \text { HW } & \end{array}$


Competing interests. The authors declare that they have no conflict of interest.

Author contributions. Yunyun Jin, Xianyong Lan, and Hong Chen designed the study and wrote the paper. Yunyun Jin performed the experiments. Hanfang Cai, Chuzhao Lei, and Hong Chen analyzed the data. Yunyun Jin did the statistical analysis. Jiming Liu, Fengpeng Lin, Xinglei Qi, and Yueyu Bai collected the samples. Xianyong Lan and Hong Chen edited and reviewed the paper.

Acknowledgements. This work was supported by the National Natural Science Foundation of China (no. 31672400), Science and Technology Coordinator Innovative Engineering projects of Shaanxi Province (2014KTZB02-02-02-02), the program of National Beef Cattle and Yak Industrial Technology System (no. CARS-38), bio-breeding capacity building and industryspecific projects from the National Development and Reform Commission (2014-2573), and specific projects of Science and Technology in Henan Province (141100110200).

Edited by: S. Maak

Reviewed by: two anonymous referees

\section{References}

Aslan, O., Hamill, R. M., Mullen, A. M., Davey, G. C., Gil, M., Gladney, C. D., and Sweeney, T.: Association between promoter polymorphisms in a key cytoskeletal gene (Ankyrin 1) and intramuscular fat and water-holding capacity in porcine muscle, Mol. Biol. Rep., 39, 3903-3914, 2012.

Bhagavati, S., Song, X., and Siddiqui, M. A. Q.: RNAi inhibition of Pax3/7 expression leads to markedly decreased expression of muscle determination genes, Mol. Cell. Biochem., 302, 257-262, 2007.

Buckingham, M. and Rigby, P. W. J.: Gene regulatory networks and transcriptional mechanisms that control myogenesis, Dev. Cell., 28, 225-238, 2014.

Buroker, N. E.: Computational STAT4 rSNP analysis, transcriptional factor binding sites and disease, Bioinformatics and Diabetes, 1, 18-53, doi:10.14302/issn.2374-9431.jbd-15-890, 2016.

Cai, H., Wang, Z., Lan, X., Xu, Y., Chen, H., and Lei, C.: Indels within the bovine visfatin gene affect its mRNA expression in longissimus muscle and subcutaneous fat, Arch. Anim. Breed, 59, 91-95, 2016.

Chen, J. F., Tao, Y., Li, J., Deng, Z., Yan, Z., Xiao, X., and Wang, D. Z.: microRNA-1 and microRNA-206 regulate skeletal muscle satellite cell proliferation and differentiation by repressing Pax7, J. Cell. Bio., 190, 867-879, 2010.

Chen, Y., Gelfond, J., McManus, L. M., and Shireman, P. K.: Temporal microRNA expression during in vitro myogenic progenitor cell proliferation and differentiation: regulation of proliferation by miR-682, Physiol. Genomics, 43, 621-630, 2011.

Chorley, B. N., Wang, X., Campbell, M. R, Pittman, G. S., Noureddine, M. A., and Bell, D. A.: Discovery and verification of functional single nucleotide polymorphisms in regulatory genomic regions: current and developing technologies, Mutat. Res-Rev. Mutat., 659, 147-157, 2008.

Cieslak, J., Flisikowska, T., Schnieke, A., Kind, A., Szydlowski, M., Switonski, M., and Flisikowski, K.: Polymorphisms in the promoter region of the adiponectin (ADIPOQ) gene are presumably associated with transcription level and carcass traits in pigs, Anim. Genet., 44, 340-343, 2013.

Dang, Y., Li, M., Yang, M., Cao, X., Lan, X., Lei, C., Lin, Q., and Chen, H.: Identification of bovine NPC1 gene cSNPs and their effects on body size traits of Qinchuan cattle, Gene, 540, 153160, 2014.

Davicioni, E., Anderson, M. J., Finckenstein, F. G., Lynch, J. C., Qualman, S. J., Shimada, H., Schofield, D. E., Buckley, J. D., Meyer, W. H., Sorensen, P. H. B., and Triche, T. J.: Molecular classification of rhabdomyosarcoma-genotypic and phenotypic determinants of diagnosis: a report from the Children's Oncology Group, Am. J. Pathol., 174, 550-564, 2009.

Dey, B. K., Gagan, J., and Dutta, A.: miR-206 and -486 induce myoblast differentiation by downregulating Pax7, Mol. Cell. Biol., 31, 203-214, 2011.

Du, E. and Hao, J.: Zinc finger protein 354C transcriptionally downregulates Fam20c during osteoblast differentiation; the society of craniofacial genetics and developmental biology 36th annual meeting, Am. J. Med. Genet. A, 164, 1879-1879, 2014.

Galli, L. M., Knight, S. R., Barnes, T. L., Doak, A. K., Kadzik, R. S., and Burrus, L. W.: Identification and characterization of subpopulations of Pax3 and Pax7 expressing cells in developing chick somites and limb buds, Dev. Dynam., 237, 1862-1874, 2008.

Gilbert, R. P., Bailey, D. R., and Shannon, N. H.: Linear body measurements of cattle before and after 20 years of selection for postweaning gain when fed two different diets, J. Anim. Sci., 71, 1712-1720, 1993.

Hyatt, J. P. K., McCall, G. E., Kander, E. M., Zhong, H., Roy, R. R., and Huey, K. A.: PAX3/7 expression coincides with MyoD during chronic skeletal muscle overload, Muscle Nerve, 38, 861866, 2008.

Jia, W., Wu, X., Li, X., Xia, T., Lei, C., Chen, H., Pan, C., and Lan, $\mathrm{X}$.: Novel genetic variants associated with mRNA expression of signal transducer and activator of transcription 3 (STAT3) gene significantly affected goat growth traits, Small Ruminant Res., 129, 25-36, 2015.

Jostes, B., Walther, C., and Gruss, P.: The murine paired box gene, $\mathrm{Pax} 7$, is expressed specifically during the development of the nervous and muscular system, Mech. Develop., 33, 27-37, 1990.

Lan, X. Y., Pan, C. Y., Chen, H., Zhang, C. L., Li, J. Y., Zhao, M., Lei, C. Z., Zhang, A. L., and Zhang, L.: An AluI PCR-RFLP detecting a silent allele at the goat POU1F1 locus and its association with production traits, Small Ruminant Res., 73, 8-12, 2007.

Lang, D., Powell, S. K., Plummer, R. S., Young, K. P., and Ruggeri, B. A.: PAX genes: roles in development, pathophysiology, and cancer, Biochem. Pharmacol., 73, 1-14, 2007.

Li, M. X., Sun, X. M., Zhang, L. Z., Wang, J., Huang, Y. Z., Sun, Y. J., Hu, S. R., Lan, X. Y., Lei, C. Z., and Chen, H.: A novel c.$274 \mathrm{C}>\mathrm{G}$ polymorphism in bovine SIRT1 gene contributes to diminished promoter activity and is associated with increased body size, Anim. Genet., 44, 584-587, 2013.

Maltzahn, J. V., Jones, A. E., Parks, R. J., and Rudnicki, M. A.: Pax7 is critical for the normal function of satellite cells in adult 
skeletal muscle, P. Natl. Acad. Sci. USA., 110, 16474-16479, 2013.

Minchin, J. E. N. and Hughes, S. M.: Sequential actions of Pax3 and Pax7 drive xanthophore development in zebrafish neural crest, Dev. Biol., 317, 508-522, 2008.

Morgante, M., Rafalski, A., Biddle, P., Tingey, S., and Olivieri, A. M.: Genetic mapping and variability of seven soybean simple sequence repeat loci, Genome, 37, 763-769, 1994.

Mottagui-Tabar, S., Faghihi, M. A., Mizuno, Y., Engström, P. G., Lenhard, B., Wasserman, W. W., and Wahlestedt, C.: Identification of functional SNPs in the 5-prime flanking sequences of human genes, BMC Genomics, 6, 1, doi:10.1168/1471-2164-6-18, 2005.

Nei, M. and Roychoudhury, A. K.: Sampling variances of heterozygosity and genetic distance, Genetics, 76, 379-390, 1974.

Sambrook, J. and Russell, D. W.: Molecular cloning: a laboratory manual, 3rd edition., Vol. 3, Coldspring-Harbour Laboratory Press, UK, 2001.

Seale, P. and Rudnicki, M. A.: A new look at the origin, function, and "stem-cell" status of muscle satellite cells, Dev. Bio., 218, 115-124, 2000.

Seger, C., Hargrave, M., Wang, X., Chai, R. J., Elworthy, S., and Ingham, P. W.: Analysis of Pax7 expressing myogenic cells in zebrafish muscle development, injury, and models of disease, Dev. Dynam., 240, 2440-2451, 2011.

Sham, P., Bader, J. S, Craig, I., O’Donovan, M., and Owen, M.: DNA pooling: a tool for large-scale association studies, Nat. Rev. Genet., 3, 862-871, 2002.

Shi, T., Peng W. W., Yan J. Y., Cai, H. F., Lan, X. Y., Lei, C. Z., Bai, Y. Y., and Chen, H.: A novel $17 \mathrm{bp}$ indel in the SMAD3 gene alters transcription level, contributing to phenotypic traits in Chinese cattle, Arch. Anim. Breed., 59, 151-157, 2016.

Tang, S., Ou, J., Sun, D., Zhang, Y., and Xu, G.: A novel 62 bp indel mutation in the promoter region of transforming growth factorbeta 2 (TGFB2) gene is associated with body weight in chickens, Anim. Genet., 42, 108-112, 2011.

Wang, K., Wang, H., Wang, J., Xie, Y., Chen, J., Yan, H., Liu, Z., and Wen, T.: System approaches reveal the molecular networks involved in neural stem cell differentiation, Protein Cell, 3, 213224, 2012.
Wu, X., Jia, W., Zhang, J., Li, X., Pan, C., Lei, C., Dang, R., Chen, H., and Lan, X.: Determination of the novel genetic variants of goat STAT5A gene and their effects on body measurement traits in two Chinese native breeds, Small Ruminant Res., 121, 232243, 2014.

$\mathrm{Xu}$, Y.: Whole genome analysis of Chinese cattle and the dosage effects of the skeletal muscle involving genes, dissertation for doctor degree, Northwest Agriculture \& Forestry University, 2014 (in Chinese).

Xu, Y., Liu, J., Lan, X., Zhang, Y., Lei, C., Zhang, C., Yang, D., and Chen, H.: Consistent effects of single and combined SNP (s) within bovine paired box 7 gene (Pax7) on growth traits, J. Genet., 1-5, 2011.

Xu, Y., Zhou, Y., Wang, N., Lan, X., Zhang, C., Lei, C., and Chen, H.: Integrating haplotypes and single genetic variability effects of the Pax7 gene on growth traits in two cattle breeds, Genome, 56, 9-15, 2012.

Yang, M., Qu, L., Liu, J., Lan, X., Zhang, L., Wang, J., Lei, C., and Chen, H.: Polymorphisms and effects on growth traits of the SH2B1 gene in Chinese cattle, Livest. Sci., 143, 283-288, 2012.

Yang, Q., Zhang, S., Liu, L., Cao, X., Lei, C., Qi, X., Lin, F., Qu, W., Qi, X., Liu, J., Wang, R., Chen, H., and Lan, X.: Application of mathematical expectation (ME) strategy for detecting low frequency mutations: An example for evaluating $14 \mathrm{bp}$ insertion/deletion (indel) within the bovine PRNP gene, Prion, 10, 409-419, doi:10.1080/19336896.2016.1211593, 2016.

Zhang, S., Han, R. L., Gao, Z. Y., Zhu, S. K., Tian, Y. D., Sun, G. R., and Kang, X. T.: A novel $31 \mathrm{bp}$ indel in the paired box 7 (PAX7) gene is associated with chicken performance traits, Brit Poultry Sci., 55, 31-36, 2014.

Zhang, S., Dang, Y., Zhang, Q., Qin, Q., Lei, C., Chen, H., and Lan, X.: Tetra-primer amplification refractory mutation system PCR (T-ARMS-PCR) rapidly identified a critical missense mutation (P236T) of bovine ACADVL gene affecting growth traits, Gene, 559, 184-188, 2015. 